\title{
Sport for all seasons, a new philosophy
}

\author{
Michael Turner
}

Not long ago, strawberries and raspberries had a limited summer season, which was eagerly anticipated and never seemed to last long enough. Salads were exclusively a feature of summer lunches (lettuces did not stay fresh in storage) and winter saw a seemingly endless supply of root vegetables (which did store well and most people hated with a passion). Now we expect to have a choice of produce that takes no account of the season and relies on our fruits and vegetables collecting more air miles than Charley Veley (reputed to be the most travelled man in the world having visited 807 of the 871 countries in the world (Observer, 28 February 2010)).

The same applies to modern professional and elite sport; what was once the off season (a time to take a holiday and relax) is now an opportunity for athletes and teams to tour abroad and to compete at the highest level. In Great Britain, all the major professional sports (soccer, tennis, horseracing, cricket and rugby) involve an 11+ month commitment with preseason camps and postseason overseas tours in the southern hemisphere, Japan, USA and India. Indeed there are only 2 days every year when horse racing does not take place somewhere in Great Britain (Christmas Day and Easter Sunday).

Despite the lack of longitudinal exposure studies in professional sport, it is logical to expect that the additional workload on the 21st century athlete will increase the potential for acute injury and the early onset of osteoarthritis. The improved management of acute injuries may mitigate some of the problems generated by this workload, but it cannot eradicate the problem completely. The enormous pressure to return these injured athletes to sport as early as possible is overwhelming, and doctors are at centre stage in this process. The popularity for 'quick-fix' total meniscectomies in the 1960s and 1970s has left a legacy in sport that will

Correspondence to Dr Michael Turner, Lawn Tennis Association, 100 Priory Lane, London SW15 5JQ, UK; Michael.Turner@LTA.org.uk provide work for knee surgeons for many years to come, but what have we learnt since then?

Before anyone submits to surgery, it is incumbent on the surgeon and anaesthetist to explain exactly what is involved and what all the possible complications might be. Indeed, under British common law, informed consent has not been legally obtained without this process being completed in a formal and structured way. However, following surgery, sports medicine seems to go into hyperdrive in an effort to return the athlete to play. Accelerated rehabilitation programmes proliferate and doctors encourage their patients to get 'back to normal' as quickly as possible, regardless of the evidence base. Nowhere is this more evident than in the management of anterior cruciate ligament (ACL) and meniscal injuries.

Following any ACL or significant meniscal injury, the knee is irreparably damaged and even repairing the ligament or meniscus does not return the joint to its preinjury state. This damage will lead to the premature onset of osteoarthritis in the damaged knee, and this process can only be accelerated by a return to intense training and competition. Is it not just as important at this stage to get additional informed consent from the player before $\mathrm{s} /$ he decides to return to elite sport?

In the past 10 years, over 3100 articles have been published in the peer review literature on ACL injuries, and yet many doctors tacitly or actively encourage players to return to professional sport in the full knowledge that this is not in the player's best long-term interest (medically).

When a smoker has a coronary thrombosis we would strongly encourage them to stop smoking; why is the sporting situation any different?

Should the decision to return to professional sport not be made by the player alone and should not the sports physician (and orthopaedic surgeon) actually declare that this is not a course of action that they can support, let alone recommend?
We surely need to apply the same stringent rules about informed consent to the postsurgery situation as we do for the preoperative scenario. A 'return to sport' consent form should be mandated for every patient who undergoes sport-related surgery, and the form should clearly identify all the short and long-term risks involved in this course of action. There is ample evidence from the past 5 years alone to highlight the long-term risks associated with meniscal damage and ACL injury. ${ }^{1-7}$

I have not recommended a return to sport for any elite athlete who has had an ACL injury in the past 10 years and this is clearly documented in the patient's notes. The fact that I have a low success rate, and that none of these patients has taken the slightest notice of my dire predictions (all of them returned to elite level sport), is hopefully a testament to the universally accepted 'play now-pay later' philosophy and not a reflection on my poor counselling skills. However, in the same way that a packet of cigarettes should always carry a health warning, I should perhaps add a small caveat-'Any team physician who has a high success rate in this area is likely to lose their job.'

Provenance and peer review Not commissioned; externally peer reviewed.

Competing interests None.

Accepted 4 January 2011

Published Online First 3 February 2011

Br J Sports Med 2011;45:235.

doi:10.1136/bjsm.2010.082289

\section{REFERENCES}

1. Keays SL, Newcombe PA, Bullock-Saxton $\mathrm{JE}$, et al. Factors involved in the development of osteoarthritis after anterior cruciate ligament surgery. Am J Sports Med 2010;38:455-63.

2. Ait Si Selmi T, Fithian D, Neyret P. The evolution of osteoarthritis in 103 patients with $\mathrm{ACL}$ reconstruction at 17 year follow-up. Knee 2006;13:353-8.

3. Seon JK, Song EK, Park SJ. Osteoarthritis after anterior cruciate ligament reconstruction using patellar tendon autograph. Int Ortho 2006;30:94-8.

4. Kessler MA, Behrend H, Henz S, et al. Function, osteoarthritis and activity after ACL-rupture: 11 years follow-up results of conservative versus reconstructive treatment. Knee Surg Sports Traumatol Arthrosc 2008;16:442-8.

5. Lohmander LS, Roos EM. Clinical update: treating osteoarthritis. Lancet 2007:370:2082-4.

6. van der Hart CP, van den Bekerom MP, Patt TW. The occurrence of osteoarthritis at a minimum of ten years after reconstruction of the anterior cruciate ligament. J Orthop Surg Res 2008;3:24.

7. Neuman P, Englund M, Kostogiannis I, et al. Prevalence of tibiofemoral osteoarthritis 15 years after non-operative treatment of anterior cruciate ligament injury: a prospective cohort study. Am J Sports Med 2008;36:1717-25. 